\section{Europe and direct-to-consumer genetic tests}

\author{
Heidi Carmen Howard and Pascal Borry
}

In a recent Ethics watch article in this journal (Ethics watch: Direct-access genetic testing: the view from Europe. Nature Reviews Genetics 12, $670(2011))^{1}$, a call for a more detailed investigation of direct-to-consumer (DTC) genetic testing in Europe was made in order to enable enforcement of a more targeted European regulation. In this contribution, we want to support this position and provide additional important details.

Although DTC genetic-testing services are currently being offered in Europe through a limited number of companies only, this issue has been raised in debates at many levels. At the European level, the European Society of Human Genetics has addressed the topic several times ${ }^{2-4}$. A report was also prepared by the Science and Technology Options Assessment for the European Parliament ${ }^{5}$. Furthermore, the European Academies of Science and the Federation of European Academies of Medicine have currently set up a working group to provide orientations at the European level.

At the national level, national bioethics committees in Belgium, France, Portugal and Austria have addressed the issue ${ }^{6-8}$. Furthermore, there have been additional statements made by various national organizations. To give some examples: the Swiss Society of Medical Genetics has published a statement on DTC genetic testing ${ }^{9}$; in Germany, DTC genetic testing has been discussed in a report elaborated by German National Academy of Sciences ${ }^{10}$; and in the United Kingdom, after several reports from the Advisory Committee on Genetic Testing and the Human Genetics Commission, a Common Framework of Principles for DTC genetic-testing services ${ }^{11}$ was presented as a way of promoting higher standards in the provision of DTC genetic tests. However, it should also be stated that the Professional and Public Policy Committee of the European Society of Human Genetics criticized these guiding principles because they "focus too much on the requirements the test providers should fulfill while paying too little attention to the quality of the genetic tests that are being sold"12.
The widespread and ongoing debate regarding DTC genetic testing is partly caused by the inadequate regulatory mechanisms that are currently in place. Various European regulations (for example, regarding data protection, electronic commerce, in vitro diagnostic medical devices and consumer protection) can already be applied to DTC genetic testing. However, these regulations have not proved to be useful in the context of the way that these services are offered: that is, via the Internet. National legislation in France, Germany, Portugal and Switzerland states that genetic tests for health purposes should only be offered under medical supervision and with genetic counselling. In these countries, attention is placed on the need for individuals to be given the opportunity to make their decisions freely and based on adequate information about the limitations of (DTC) genetic tests and their implications (which may be physical, psychological or social). This position is in line with the latest developments within Europe regarding the regulatory control of genetic testing - specifically, the introduction in 2008 of the Council of Europe's additional protocol regarding genetic testing for health purposes $^{13}$. In addition, the Netherlands have a unique permit system that guarantees normative criteria for DTC genetic tests that are aimed at detecting risk indicators of cancer and risk indicators of untreatable diseases ${ }^{14}$. Although such national legislation cannot control Internet orders, it clearly makes it very difficult or impossible for DTC companies to operate from these countries.

\section{Heidi Carmen Howard is at the Institute for BioMedical Ethics, University of Basel, Missionstrasse 24, $\mathrm{CH}-4055$ Basel, Switzerland.}

Pascal Borry is at the Department of Clinical Genetics and Department of Medical Humanities, VU University Medical Center and EMGO Institute for Health and Care Research, The Netherlands; and the Centre for Biomedical Ethics and Law, Katholieke Universiteit Leuven, Kapucijnenvoer 35, BOX 7001, 3000 Leuven, Belgium.

e-mails: heidi.howard@unibas.ch; pascal.borry@med.kuleuven.be doi: 10.1038/nrg3073-c1

Published online 13 December 2011

1. Kricka, L. J,. Fortina, P,. Mai, Y. \& Patrinos, G. P. Ethics watch: Direct-access genetic testing: the view from Europe. Nature Rev. Genet. 12, 670 (2011).

2. European Society of Human Genetics. Statement of the ESHG on direct-to-consumer genetic testing for health-related purposes. Eur. J. Hum. Genet. 18, 1271-1273 (2010).

3. van El, C. G. \& Cornel, M. C. Genetic testing and common disorders in a public health framework. Eur. J. Hum. Genet. 19, 377-381 (2011).

4. Becker, F. et al. Genetic testing and common disorders in a public health framework: how to assess relevance and possibilities. Eur. J. Hum. Genet. 19, S6-S44 (2011).

5. European Parliament. Science and Technology Options Assessment. Direct to consumer genetic testing study. Institute of Science and Technology (Belgium) [online], http://www.

samenlevingentechnologie.be/ists/nl/pdf/rapporten/ final_report_direct_to_consumer_testing_stoa.pdf (2008).

6. Belgian Advisory Committee on Bioethics. Opinion no. 32 of 5 July 2004 on the free availability of genetic tests. Federal Public Service: Health, Food Chain Safety and Environment (Belgium) [online], http://www. health.belgium.be/ filestore/13084478/Opinion $\% 2032 \% 20$ web 013084478 en.pdf (2004).

7. National Council for Ethics in the Life Sciences. Opinion no 56 of the National Council of Ethics for the Life Sciences. Opinion on direct marketing of genetic tests to the public. CNECV [online], http://www.cnecv.pt/admin/files/data/ docs/1273504469 56CNECV2008 EN.pdf (2008).

8. Austrian Bioethics Commission. Genetic and genome-wide testing on the Internet: report of the Austrian Bioethics Commission on Internet-based genetic and genome-wide testing. Federal Chancellery Austria [online], http://www.bka.gv.at/ DocView. axd? Cobld = 40383 (2010).

9. Fokstuen, S. \& Heinimann, K. Tests génétiques sur Internet. Bulletin des médecins suisses 90 , 328 (2009).

10. German National Academy of Sciences. Predictive genetic diagnostics as an instrument of disease prevention. Leopoldina [online], http://www.leopoldina.org/fileadmin/user_upload/ Politik/Empfehlungen/Nationale_Empfehlungen/ Praed_gen diagnostik_stellungnahme_lang_EN.pdf (2010).

11. Human Genetics Commission. A common framework of principles for direct-to-consumer genetic testing services. Human Genetics Commission [online], http://www.hgc.gov.uk/Client/document. asp? Docld $=280$ \&CAtegoryld $=10$ (2010)

12. Professional and Public Policy Committee of the European Society of Human Genetics. Letter to the Human Genetics Commission. European Society of Human Genetics [online], https://www.eshg.org/ fileadmin/www.eshg org/documents/PPPC-ESHC DTC-06122009.pdf (2009)

13. Council of Europe. Additional protocol to the convention on human rights and biomedicine, concerning genetic testing for health purposes. Council of Europe Treaty Office [online], http://conventions.coe.int/Treaty/en/Treaties/ html/203.htm (2008).

14. van Hellemondt, R. E,. Hendriks, A. C. \& Breuning, $\mathrm{M}$. H. Regulating the use of genetic tests: is Dutch law an example for other countries with regard to DTC genetic testing? Amsterdam Law Forum 3, 13-24 (2011).

\section{Acknowledgements}

H.C.H. is funded by the European Commission FP7 Marie Curie initiative.

Competing interests statement

The authors declare no competing financial interests. 